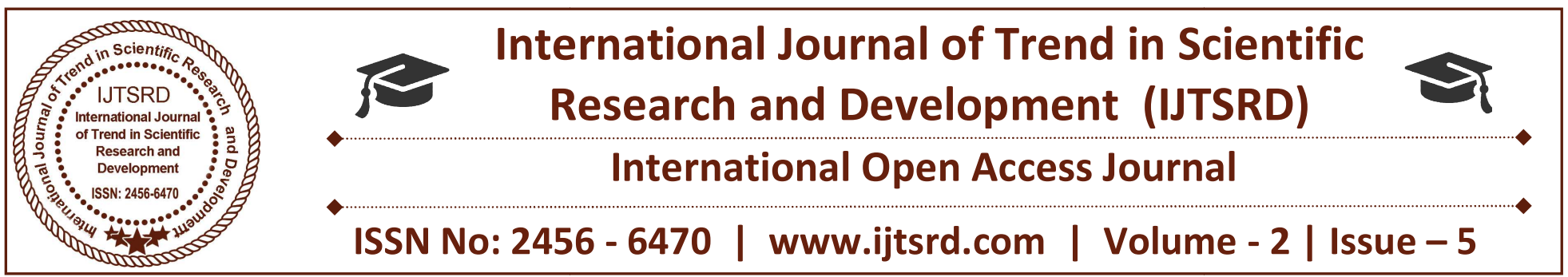

\title{
Rights of Refugees in India
}

\author{
Bhavika Madnani \\ B.B.A., LL.B. (Hon), Indore Institute of Law, \\ Indore, Madhya Pradesh, India
}

\begin{abstract}
The researcher has done the research on rights of refugees in India. The International Convention dealing with the issue of refugees is the 1951 Convention on Status of Refugees and the 1967 Protocol attached to it. The term 'refugee' is defined as "...a person owing to well-founded fear of being persecuted for reasons of race, religion, nationality, membership of a particular social group or political opinion, is outside the country of his nationality and is unable or, owing to such fear, is unwilling to avail himself of that protection of that country; or who, not having a nationality and being outside a country of his former habitual residence as a result of such events, is unable or, owing to such fear, unwilling to return to it."
\end{abstract}

The research contains the history of refugees in India and also analyses the problems faced by refugees then in addition to it the researcher has given brief idea about India's Stance in 1951 Convention, how India entered in the UN in 1951 and the stand of it.

Following up what is the refugee status in India is explained through constitutional protection, laws in India and of Judiciary, UNHCR and NHRC in India, International laws and conventions on Refugees and the India's Refugee Policy.

\section{INTRODUCTION}

Human Rights of Refugees are one of the major problems of the world. According to Article 1 of United Nations Convention on Status of Refugees, refugees are those who are "owing to a well-founded fear of being persecuted for reasons of race, religion, nationality, membership of a particular social group, or political opinion, is outside the country of his nationality, and is unable to or, owing to such fear, is unwilling to avail himself of the protection of that country."

They move to other countries when their life is in constant threat due to various reasons and not perfect for their healthy survival. Many countries in the world have a proper rule governing refugees living in their country and the protection that should be given to them but in India, there is no uniform legal framework. India is a country where there are many refugee groups from different countries, majorly from its neighbouring countries. It doesn't have any suitable refugee rule $\mathrm{s}$ and is neither a signatory to the 1951 UN Convention nor 1967 protocol on Status of Refugees. Many countries have adopted binding regional instruments for the protection of refugees, but there is no instrument to protect the refugees of the Asian region. India has followed ad-hoc policies about refugee settlements since its independence. There are a large number of refugees in India due to its geographic location, religious society, vast culture. Currently, Rohingya refugees are a major concern to India. There are numerous aspects pertaining to refugees which are of major importance both to India, as a country and to the refugees, particularly in the context of law implementation. UNHRC and HNRC are the bodies of Human Rights of the UN and India respectively. Major Refugee issue in India was because of the India-Pakistan partition of 1947, when there were millions of population exchanges between these newly formed countries. Some major Refugee groups in India are from Iran, Tibet, Bangladesh, Pakistan, Afghanistan, Sri Lanka, Myanmar.

Jordan, Pakistan, Ethiopia, Iran, Turkey host the largest number of refugees as of 2016.Refugee protection is a great concern to the international 
community ever since the formation of the United Nations and the issue hasn't been solved yet. Migration was a problem ever since the ancient times. Tribal people migrated in search of food, water, and resources, now the refugees migrate for safety and other reasons. There are 15.2 million refugees worldwide and 1 million are waiting for their asylum application approvals

\section{HISTORY OF REFUGEES IN INDIA}

India is a very vastly populated country and is one of the countries experiencing refugees lately. Migrations in the past occurred due to the Hindukush Mountains in the west and Patkoi ranges in the east. Partition of India-Pakistan resulted in a huge number of people migrating. Almost 20 million came to India after India got its Independence. It had to set up many relief camps addressing the huge number of refugees. People started coming in from Bangladesh, Pakistan. It passed the Rehabilitation Financial Administration Act in the year 1948 to address these issues with funding. A Huge number were displaced from India to Pakistan and vice versa and the problem was much similar to Refugees. Another instance was in 1959 when Dalai Lama and his followers approached India as refugees and India provided them a Political Asylum. The year of 1971 saw many refugees travelling from East Pakistan to India. In 1983 and 1986 India had refugees coming in from Sri Lanka and Bangladesh respectively. At the end of 1992, India has hosted 2,000,000 migrants and 237,000 displaced persons. India always has some or the other Refugees coming in throughout its history.

\section{PROBLEMS FACED BY REFUGEES}

Refugees who needed up in different refugee camps or different countries face any problems with their life. They are subject to harsh living conditions. They have limited resources, live in tents, have limited food, water, clothing. They live without adequate shelter and face many difficulties. Those who do not join refugee camps and join countries, often face unexpected hardships, they also face cultural, language problems. The refugee children are the ones facing the most of the problems. They find it very hard to continue with schooling and fail to understand and cope up. Most refugees take up some or the other labour work in the country they are living and are exploited by the recruiters. They feel unsafe in their country, because of which they come to the new place, but feel unhappy and unsafe here as well. Different countries have different set of rules handling refugees, some countries grant citizenship in less number of years than the other. The perks of being a refugee in one country are different than the other. They face discrimination, financial difficulties, and are psychologically affected.

\section{INDIA'S STANCE IN 1951 CONVENTION}

There are 144 signatories to the 1951 Refugee Convention, and India is not one of them. The Refugee Convention is about the rights of individuals who are refugees in other countries and the responsibilities of the nation hosting them. India faces a lot of pressure from International bodies about it not being a signatory to the Refugee convention. Taking into consideration, the political, economic, ethical factors prevent India from being a party to 1951 Refugee Convention. India is a developing country and it would be a burden if it complies with the convention and becomes a signatory, and affect the security laws of India. It felt the convention is not related to the problems arising in India, but it is applying some articles from the 1951 convention. India believes even if it's not a signatory, it would provide minimum reeds for a refugee. India has many problems with its border sharing countries, due to which it took that decision. If it becomes a signatory, it will have to provide more and more resources and other things for the refugees. After 1991, due to the execution of Rajiv Gandhi by a Sri Lankan refugee, India supported its stance for the very same reason. Refugees damage the economy of India as well, as many come to India in search of opportunities. It is afraid that people may come to the country names as refugees for various reasons and misuse the convention for better opportunities. Should India be a signatory to the Refugee Convention or its Protocol is still a question that has both pros and cons.

\section{REFUGEE STATUS IN INDIA CONSTITUTIONAL PROTECTION}

A few articles of the Constitution of India are applicable to the refugees when they are in India. The most important Article is Article 21 which deals with Right to Life and personal liberty; it applies to everyone irrespective of whether they are a citizen of India. Many judgements have been given based on Article 21 on refugees. Article 14 guarantees the person right to equality before the law. Article 5, 6, 7, $8,9,10,11,12,20,22,25-28,32,226$ also available for non-citizens of India including Refugees. In the case of Louis De Raedt v. Union of India, the court held that the fundamental rights to life, liberty, dignity 
are available to non-citizens of India. In the case of Visakha v. State of Rajasthan, the court has held that "International Conventions and norms are significant for the purpose of interpretation of the guarantee of gender equality, right to work with human dignity in Articles 14, $1519(1)(\mathrm{g})$ and 21 of the Constitution and the safeguards against sexual harassment implicit therein".Some fundamental rights are guaranteed to non-citizens of India. In the case of NHRC v. State of Arunachal Pradesh, the government was asked by the court to safeguard the life, health, of Chakmas that are in the state and that their application for citizenship should be sent to the authorities concerned immediately. There are definitely a number of protections to the refugees living in India according to the Constitution of India but are hardly in practice. The cases and the provisions of the Constitution gives a hint about intention to help refugees, but due to India's own reasons it doesn't sign any Conventions related to it.

\section{LAWS IN INDIA AND LAW OF JUDICIARY}

We only have the Refugee and Asylum (Protection) Bill of 2009, no definite legislation regarding Refugees is available in India but the main legislation that supports is the Foreigners Act of 1946 which on the difference of Alien and Refugee create further persecution of the Refugee. The laws related to refugees are

$>$ Citizenship Act, 1955 (No.57 of 1955)

$>$ Extradition Act, 1962 (No. 34 of 1962)

$>$ Foreigners Act, 1946 (No.31 of 1946)

$>$ Illegal Migrant (Determination by Tribunals) Act, 1983 (No.39 of 1983)

$>$ India Penal Code Act, 1860 (No.45 of 1860)

$>$ Passport (Entry into India) Act, 1920 (No.34 of 1920)

$>$ Passport Act, 1967 (No.15 of 1967)

$>$ Protection of Human Rights Act, 1993 (No.10 of 1994)

$>$ Registration of Foreigners Act, 1939 (No.16 of 1939).

Refugees are considered under the term 'alien' in India. The term appears in Constitution of India (Article 22), Section 83 of the Indian Civil Procedure Code, Section 3(2)(b) of the Indian Citizenship Act, 1955, as well as some other statutes. Most of the acts cause further complications to the refugees. The Foreigners Act, 1946 give the officials power to arrest or detain any foreigner on mere suspicion for noncompliance. The current laws in India are not sufficient in order to protect refugees and need a much greater law for the protection of refugees. According to the Principle of Non-Refoulment, no country shall deport, expel or forcefully return the refugee back to his original territory against his will or if there is a reasonable threat to his life, liberty and freedom.

Judiciary plays an important role in protecting refugees, many cases gave landmark judgements regarding refugees. The judiciary has made it easy with the concepts of Social Action Litigation and Public Interest Litigation.

Right to basic amenities: In Digbijay Mote v. Union of India, an NGO was running a school for the Sri Lankan refugees, When PIL was made when the condition to run the school was difficult, Ministry of Women and Social Welfare provided financial assistance to the school. In Majid Ahmed Abdul MajidMohdJad Al Hak v. Union of India, basic amenities like food and medicines must be provided to the refugees who are in detention.

Non-Refoulment and Right to refugee Status: In MalvikaKarelkar v. Union of India, the deportation order issued against 21 Burmese refugees were stayed by the SC and allowed them to seek refugee status under UNHCR.

\section{UNHCR AND NHRC IN INDIA}

UNHCR in India is participating very actively as the number of cases regarding refugees is increasing day by day. If some refugee goes back to his country after being a refugee in India, UNHCR watches if the person is going back voluntarily. It performs the function of determination of refugee along with providing resources to them. UNHCR got involved since the issue of Tibetan refugees and the Bangladesh crisis in 1971. The Delhi office of the UNHCR works to help refugees become selfsufficient with assistance and income-generating activates with the help of NGO's. The main role of UNHCR in India is to make sure that the refugees are not forced to go back to their country from which they have fled until the issue rests in their country.

NHRC i.e., National Human Rights Commission in 1994, gave directions to Tamil Nadu Government to provide medical help to Sri Lankan refugees. In 1995, it filed a PIL on Arunachal Pradesh Government regarding the government not supporting Chakmas, 
and got the decision of the court ordering the government to provide necessary help to the group. It gets involved in all the refugee issues in India and provides some or the other help required.

\section{NEED FOR DOMESTIC LAW}

India doesn't have any separate law for the refugees, but it desperately needs one considering the recent issues and many more issues that may come in the future. Until a law is made, India continues to hold refugees depending on the country of them and political considerations. Though NHRC has submitted many reports about the need for India to have a Law based on Refugees but no response to them. A law is required so that all refugees will be handled equally and correct provisions are made for them during the crisis. The law should also include the provisions for internally displaced people as well. All existing acts that make the refugees suffer more must be replaced with this new law; the law will make the procedure for granting a refugee status easier. It will also help end the discrimination against refugees in India, and help the Refugees in all ways possible for their development.

\section{INTERPLAY OF HUMAN RIGHTS LAW, REFUGEE LAW, HUMANITARIAN LAW}

Both Refugee Law and Human Rights law often coexist and overlap each other in several fields. International Humanitarian Law and Human Rights law being the distinct branches of law overlap as well, as one deals with the protection or a person from abusive power and the other one deals with the conduct of parties to an armed conflict. In the case of protection of the person in the power of a party to the conflict both Humanitarian Law and Human Rights Law reinforce each other mutually. Humanitarian Law deals with the conflicts and while Refugee Law deals with the people that flee due to the conflicts. They both go hand in hand due to that. Coming to the Interplay of Human Rights Law and Refugee Law, both of them describe the Principle of NonRefoulment which prohibit forceful repatriation. On the whole none of the Laws work independently but go hand in hand with each other. Some of the principles or ideas are borrowed or adopted from each other as well.

\section{INTERNATIONAL LAWS CONVENTIONS ON REFUGEES}

There are any declarations, conventions, regarding refugees. Some of them are Convention relating to the
Status of Refugees (1951) and Protocol (1949), Convention relating to the status of Stateless Persons (1954), UN Declaration on Territorial Asylum (1948), Universal Declaration of Human Rights (1948), Convention on the Elimination of Discrimination against Women (1979), International Convention on Civil and Political Rights, Convention on the Reduction of Statelessness (1961), Guiding Principles on Internal Displacement (1998). Some of the Regional Refugee Laws are Cartagena Declaration (1984), Asian African Legal Consultative Committee Principles (1996).

The UN Convention Relating to the Status of Refugee of 1951 was adopted on 28 July 1951 and entered into force on 22 April 1954. It erases previous laws and set a most comprehensive codification of the rights of refugees. The Convention deals with General Provisions, Juridical Status, Gainful Employment, Welfare, Administrative measures, Executory and Transitory powers. These chapters are very well defined and the serve the purpose of helping refugees. Article 1 gives the definition to the term 'refugee', Article 12, 13 deal with Personal status and Movable and Immovable property respectfully. Article 16 deals with Access to Courts. As the 1951 Convention covers only those persons who have become refugees as a result of events occurring before 1951, Protocol relating to the Status of Refugees was entered into force on 4 October 1967, because new refugee situations have arisen after the convention and the new refugee did not fall under the Convention. So, to ensure equality of all refugees, this protocol covered that.

\section{INDIA'S REFUGEE POLICY}

The objective of immigration is gaining citizenship or nationality in a different country. In India, the provisions of the Constitution mainly govern the law relating to citizenship or nationality. The Constitution of India provides for single citizenship for the entire country. The provisions relating to citizenship are contained in Articles 5 to 11 in Part-II of the Constitution of Indian. Article 5 states that at the commencement of this Constitution, every person belonging to the following categories, who has his domicile in the territory of India, shall be a citizen of India:

$>$ Who was born in the territory of India; or

$>$ Either of whose parents was born in the territory of India; or 
Who has been ordinarily resident in the territory of India for not less than five years immediately preceding such commencement.

There are numerous aspects pertaining to refugees, which are of major importance both to India, as a country and to the refugees, particularly in the context of law enforcement. Given the security scenario prevailing in the country, particularly arising out of the role of some of the neighbor's in this regard, an utterly humanitarian matter like the 'refugees' has come to be influenced by considerations of national security.

While law and order is a State subject under the Indian Constitution, international relations and international borders are under the exclusive purview of the Union government. This has resulted in a variety of agencies, both of the Central as well as the State governments, having to deal with refugee matters connected with law enforcement. Also, all policies governing refugees are laid down by the Union government though the impact of the refugee problem as such has to be borne by the State administration to a greater degree if not wholly.

They have to make sure that the laws of the land are enforced in regard to refugees without in any way ignoring or neutralizing security considerations. But, at the same time, it is also their responsibility that the humanitarian overtones so characteristically and inseparably associated with refugees in general, are not lost sight of. It should be appreciated that a person becomes a refugee because of circumstances, which are beyond that person's control, often poignant.

She/he is left with no other option but to flee from human rights violations, socio-economic and political insecurity, generalized violence, civil war or ethnic strife all these leading to fear of persecution.

Article 1 Para. 2 of the 1951 United Nations Convention defines 'refugee' as "A person who owing to well founded fear of being persecuted for reasons of race, religion, nationality, membership of a particular social group or political opinion, is outside the country of his nationality and is unable or, owing to such fear, unwilling to avail himself of the protection of that country."

There are four well-defined groups of foreigners who are different from 'refugees'. These categories are:
Temporary Residents, Tourists and Travellers

Persons under this category come to India for a specific purpose and duration with the prior permission of the Government of India. However, in certain circumstances anyone in this category could become eligible for being a refugee, if, during their sojourn in India; the situation in their country of origin becomes such as to endanger their lives and liberty if they were to return to their country.

\section{Illegal Economic Migrants}

Any foreigner who might have left his or her country of origin without due authorization from the authorities concerned, both in the country of origin as well as the country of destination, solely to improve his or her economic prospects, is not a refugee. After all, there is no element of persecution or coercion compelling the individual to leave the country of origin.

\section{Criminals, Spies, Infiltrators, Militants etc}

None of these can ever become eligible to be refugees. They have to be dealt with under the provisions of the Indian criminal laws as well as any other special laws in force even though some of them may be in possession of valid travel documents.

\section{Internally Displaced Persons (IDP)}

Those persons, who are fleeing persecution and human rights violations from one region of the country and have sought refuge in another region of the same country, fall under this category. Such persons cannot be categorized as 'refugees' as they have not crossed any international border. Moreover, they have the protection of their national government. These persons are categorized as 'internally displaced persons' (IDP)

Even though India has been the home for a large number and variety of refugees throughout the past, it has dealt with the issues on a bilateral basis. It has been observing a 'refugee regime' which generally conforms to the international instruments on the subject without, however, giving a formal shape to the practices adopted by it in the form of a separate statute. Refugees are no doubt 'foreigners'. Even though there may be a case to distinguish them from the rest of the 'foreigners', the current position in India is that they are dealt with under the existing Indian laws, both general and special, which are otherwise applicable to all foreigners. This is because there is no separate law to deal with 'refugees'. For 
the same reason, cases for refugee 'status' are considered on a case - by - case basis. UNHCR often plays a complementary role to the efforts of the Government, particularly in regard to verification about the individual's background and the general circumstances prevailing in the country of origin. That agency also plays an important role in the resettlement of refugees etc.

\section{CONCLUSION}

In the whole world, though there are a number of conventions and laws governing refugees, the refugees still keep facing problems. When a country as big as India doesn't have a Refugee Law, we can understand that many countries have the same face and are on the same boat. If UNHCR and NHRC work together, there will be much more development in the field of Refugee Law. There is definitely a need for India to set up a Law regarding Refugees, as in the future there may be many more issues due to various reasons. Whenever UNHCR tries to do something regarding refugees NGO's should actively help them. Though protection to refugees is given under various articles of the Constitution, there needs to be a uniform Law that give equal rights to all the refugees. India continues to take the humanitarian view of the problem of the refugees. Considering the security issues due to which India is not a signatory to the 1951 Convention, it should give due consideration to the same. It should also take care that the refugee law is not mistreated and mis-utilized by persons who come to seek opportunities. Many judgements in India support the refugees. India has done a very good work regarding refugees, but needs to do much more. Many Rohingya refugees living in India are receiving support, but India is planning to deport them to their territory. In the past NHRC submitted a report for the ned for a Refuge law but didn't receive a reply. If UNHCR and NHRC together do the same, there may be an answer. The Refugee Convention and its Protocol of 1951 and 1967 are the Conventions that received global response with many countries signing the convention. They consider most of the reasons of refugees and tell us the rights and other provisions that they should be given. India on the whole, needs a refugee law for governing refugees entering India.

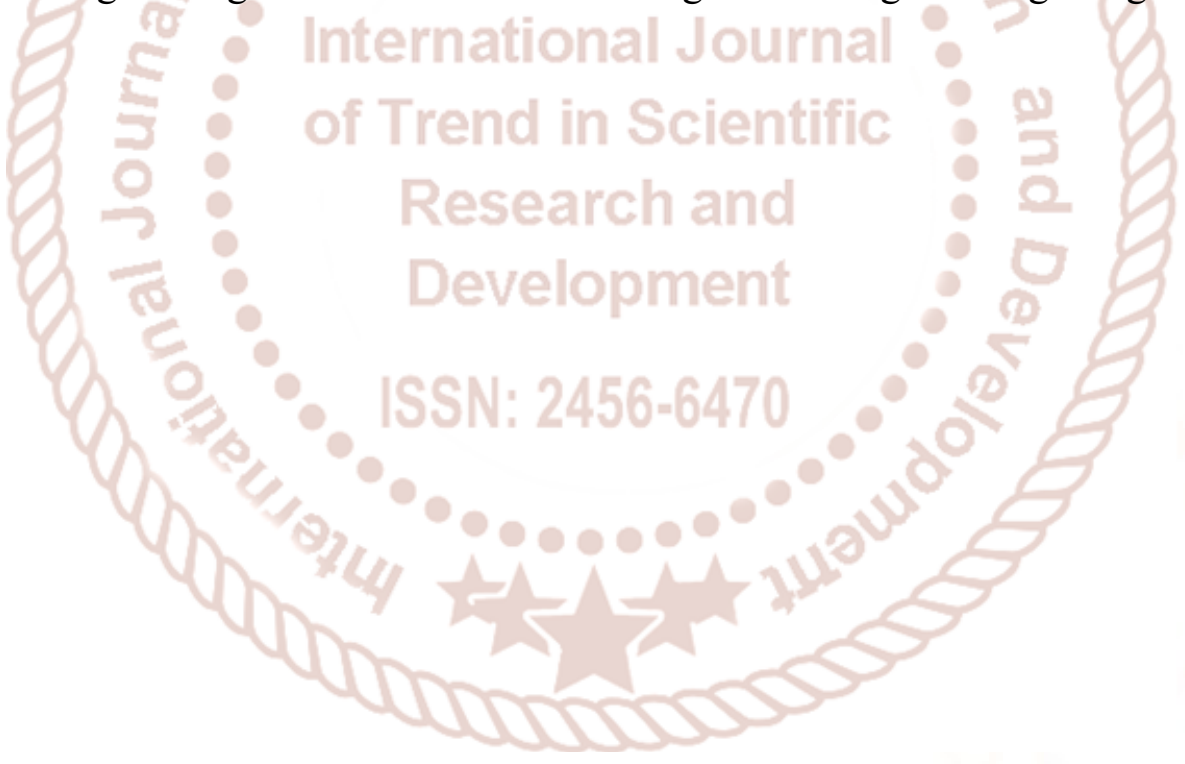

